\title{
A New Dental Superalloy System: IV. X-Ray Diffraction Analysis
}

\author{
HAMDI MOHAMMED,* KAMAL ASGAR, and O. F. KIMBALL \\ School of Dentistry, University of Michigan, Ann Arbor, Michigan 48104, USA
}

$X$-ray diffraction analysis of the alloy system Co-Ni-Cr-Ta showed that the ternary alloy base consisted of three phases $(\alpha, \beta$, and $\sigma)$. Addition of $T$ a caused a decrease in the intensity of the $\beta$ lines. Further Ta additions caused diffraction lines characteristic of the intermetallic compound $\alpha-\mathrm{Co}_{3} \mathrm{Ta}$. At higher $T$ a concentrations, the intensity of the lines characteristic of the $\sigma$ phase increased and lines characteristic of $\mathrm{Co}_{2} \mathrm{Ta}$ appeared.

Alloy design considerations discussed in part I1 of this series of articles suggested that the addition of tantalum ( $\mathrm{T}$ a) to a 40 cobalt (Co) -30 nickel (Ni) -30 chromium (Cr) alloy would result in the formation of the intermetallic compound $\mathrm{Co}_{3} \mathrm{Ta}$, which forms a coherent interface with the face-centered cubic (FCC) $\alpha$ phase. Tantalum increases the stacking fault energy (SFE) of the alloy system, thus decreasing the amounts of the less ductile, hexagonal, close-packed (HCP) $\beta$ phase. Excessive amounts of $\mathrm{Ta}$ increase the average electron hole number of the alloy $\left(\bar{N}_{v}\right)$ beyond its critical value; this causes the formation of excessive amounts of the embrittling $\sigma$ phase.

Experimental evidence obtained from metallographic examination (part III of this study) ${ }^{2}$ showed phase changes that were interpreted to be a decrease in the concentration of the $\beta$ phase and an increase in the amounts of the $\sigma$ phase. Direct evidence of these transformations, of the formation of the intermetallic compound $\alpha-\mathrm{Co}_{3} \mathrm{Ta}$, or

Based on a dissertation submitted in partial fulfillment of the PhD degree in dental materials and engineering materials at the University of Michigan, Ann Arbor, Mich.

Received for publication June 5, 1972.

- Present address: University of Connecticut, Health Center, School of Dental Medicine, Farmington, Conn 06032. of the nature of the interface between the latter precipitate and the matrix was not obtained. The purpose of this paper was to furnish X-ray diffraction evidence to support or negate the aforementioned theoretical assumptions and to test the validity of the design for the Co-Ni-Cr-Ta alloy system.

\section{Materials and Methods}

When grinding a specimen is impractical because of hardness, there are two conditions that are necessary to obtain a truly representative X-ray diffraction pattern from an alloy: the diffraction specimen must be as-cast and it must be made from the same charge used for the tensile specimen. A thin foil ${ }^{3}$ obtained by grinding a thicker one, or a thin specimen prepared from a charge similar to that of the tensile specimen, ${ }^{4}$ does not satisfy these conditions. X-ray diffraction specimens for this study were prepared from the same investment block and from the same alloy charge used for the tensile specimen. X-ray diffraction specimens were prepared by connecting two nylon bristles ${ }^{a}$ to the tensile specimen threads and riser at the feed end of the bar, as shown in the illustration. This arrangement furnished two X-ray diffraction specimens, which were 0.020 inch in diameter and 0.75 to 1.0 inch long, for each tensile specimen prepared from each of the 15 alloys used in part II of this study. ${ }^{5}$

The Debye-Scherrer powder method was used with a $114.6 \mathrm{~mm}$ diameter camera.

The choice of radiation is limited essentially by wavelength, as well as by the $K$ absorption edge of the major elements in the alloy.6,7 Inappropriate selection of $\mathrm{X}$ radiation may result in film that is foggy

\footnotetext{
a Loma Linda Parallelometer, Chayes Dental Co., Loma Linda, Calif.
} 


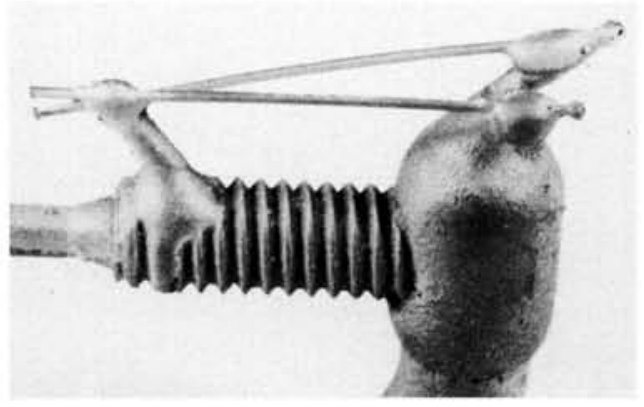

X-ray diffraction specimens, as cast.

or that has too few lines for correct interpretations.

Johnson ${ }^{4}$ found that unfiltered iron radiation was suitable for $\mathrm{Co}-\mathrm{Ni}-\mathrm{Cr}$ alloys. When we used iron, the number of lines obtained was too few to furnish the needed information. Chromium radiation yielded similar results. Molybdenum (Mo) has a much shorter $\mathrm{K}_{\alpha}$ wavelength and increased the number of lines, but it caused the coincidence of reflections of close $d$ spacings. Further, reflections for planes with $d$ spacings larger than $2.05 \mathrm{~A}$ were not obtained. Accordingly, $\mathrm{Cr}$ radiation and Mo radiation were necessary and two films were obtained for each specimen examined. Molybdenum was used at $40 \mathrm{kv}$ and $15 \mathrm{ma}$ for 18 hours and $\mathrm{Cr}$ was used at $45 \mathrm{kv}$ and $25 \mathrm{ma}$ for 24 hours.

\section{Results}

X-ray diffraction patterns were obtained from all 15 alloys by use of $\mathrm{Mo}-\mathrm{K}_{\alpha}$ radiation. In all instances the only diffraction lines obtained were those of the FCC $\alpha$ matrix phase, which is a solid solution of $\mathrm{Cr}$ in a Co FCC-Ni matrix. 8.9 X-ray diffraction data obtained from the Ta-free alloy $A_{1} B_{1}$ and alloy $A_{15} B_{15}$, which contained $16.8 \% \mathrm{Ta}$, are given in Table 1 as representative examples.

The X-ray diffraction patterns obtained with $\mathrm{Cr}-\mathrm{K}_{\alpha}$ radiation provided evidence for four additional phases. These phases are the HCP $\beta$ phase, which is a solid solution of $\mathrm{Cr}$ in a Co HCP-Ni matrix $(a=5.200 \mathrm{~A}$ and $c=6.410 \mathrm{~A})$; the intermetallic compound ${ }^{10-12} \alpha-\mathrm{Co}_{3} \mathrm{Ta}$, which is a simple cubic phase $(a=3.647 \mathrm{~A})$; the intermetallic compound $\gamma$-Co.2 $\mathrm{Ta}$, which is a HCP phase $(a=4.700 \mathrm{~A}$ and $c=15.420 \mathrm{~A})$; and the $\sigma$ phase, which is body-centered tetragonal (BCT), $(a=5.200 \mathrm{~A}$ and $c=6.410 \mathrm{~A})$.

As indicated by the data in Table 2, the pattern from the Ta-free alloy $A_{1} B_{1}$ contained lines corresponding to $\beta$ and $\sigma$ phases, in addition to those of the $\alpha$ phase. The patterns from alloys $A_{2} B_{2}, A_{3} B_{3}$, and $A_{4} B_{4}$ were substantially the same; this indicated that the addition of $\mathrm{Ta}$ in amounts up to $4.8 \%$ to the $40 \mathrm{Co}-30 \mathrm{Ni}-30 \mathrm{Cr}$ alloy base did not produce detectable amounts of additional phases.

Data obtained from the diffraction pattern of alloys $A_{5} B_{5}$ through alloy $A_{13} B_{13}$ (Tables 3,4) showed three new lines. One of these reflections (line 1) belonged to the $\sigma$ phase. The other two reflections (lines 3 and 5) correspond to strong reflections of the $\alpha \cdot \mathrm{Co}_{3} \mathrm{Ta}$ pattern.

Data obtained from the diffraction pattern of alloy $A_{15} B_{15}$ showed an additional four lines, lines $3,8,13$, and 15 in Table 5 . Line 15 is characteristic of $\alpha \cdot \mathrm{Co}_{3} \mathrm{Ta}$ compound.

TABLE 1

X-Ray Diffraction Data Obtained with Mo-K $\mathrm{K}_{a}$ Radiation

\begin{tabular}{|c|c|c|c|c|c|c|c|c|c|c|}
\hline \multirow[b]{2}{*}{ Line } & \multicolumn{5}{|c|}{ Alloy $A_{1} B_{1}(0 \% \mathrm{Ta})$} & \multicolumn{5}{|c|}{ Alloy $A_{15} B_{15}(16.8 \% \mathrm{Ta})$} \\
\hline & $2 \theta$ & $d, \mathrm{~A}$ & $I / I_{0}$ & $h k l$ & Phase & $2 \theta$ & $d, \mathrm{~A}$ & $1 / I_{0}$ & $h k l$ & Phase \\
\hline 1 & 19.96 & 2.04900 & 100 & 111 & $\alpha^{*}$ & 19.930 & 2.05250 & 100 & 111 & $\alpha^{*}$ \\
\hline 2 & 23.27 & 1.76200 & 50 & 200 & $\alpha^{*}$ & 23.280 & 1.76120 & 50 & 200 & $\alpha^{*}$ \\
\hline 3 & 33.01 & 1.25080 & 30 & 220 & $\alpha^{*}$ & 33.019 & 1.25040 & 60 & 220 & $\alpha^{*}$ \\
\hline 4 & 38.87 & 1.06790 & 80 & 311 & $\alpha^{*}$ & 38.840 & 1.06870 & 80 & 311 & $\alpha^{*}$ \\
\hline 5 & 40.66 & 1.02280 & 20 & 222 & $\alpha^{*}$ & 40.546 & 1.02540 & 30 & 222 & $\alpha^{*}$ \\
\hline 6 & 46.82 & 0.89438 & 05 & 400 & $\alpha^{*}$ & 47.170 & 0.88812 & 10 & 400 & $\alpha^{*}$ \\
\hline 7 & 51.54 & 0.81748 & 20 & 331 & $\alpha^{*}$ & 51.586 & 0.81660 & 20 & 331 & $\alpha^{*}$ \\
\hline 8 & 53.03 & 0.79597 & 20 & 420 & $\alpha^{*}$ & 53.192 & 0.79372 & 20 & 420 & $\alpha^{*}$ \\
\hline 9 & 58.44 & 0.72792 & 15 & 422 & $\alpha^{*}$ & 58.461 & 0.72769 & 15 & 422 & $\alpha^{*}$ \\
\hline 10 & 62.56 & 0.68438 & 15 & 511,333 & $\alpha^{\bullet}$ & 62.475 & 0.68517 & 15 & 511,333 & $\alpha^{\bullet}$ \\
\hline
\end{tabular}

- FCC: $a=3.545 \mathrm{~A}$. 
TABLE 2

X-Ray Diffraction Data Obtained from Alloy $A_{1} B_{1}(0 \%$ Ta) With CR-K $a$ Radiation

\begin{tabular}{cccccc}
\hline \hline Line & $2 \theta$ & $d, \mathrm{~A}$ & $I / I_{0}$ & $h k l$ & Phase \\
\hline 1 & 30.44 & 4.3632 & 50 & 100 & $\beta^{*}$ \\
2 & 41.01 & 3.2700 & 80 & 002 & $\beta^{*}$ \\
3 & 53.86 & 2.5292 & 60 & 110 & $\beta^{*}$ \\
4 & 58.92 & 2.3290 & 05 & 210 & $\sigma^{\ddagger}$ \\
5 & 61.22 & 2.2496 & 05 & 202 & $\sigma^{\dagger}$ \\
6 & 63.52 & 2.1762 & 20 & 200 & $\beta^{*}$ \\
7 & 68.07 & 2.0466 & 100 & 111 & $\alpha^{\ddagger}$ \\
8 & 74.04 & 1.9025 & 20 & 103 & $\beta^{*}$ \\
9 & 79.75 & 1.7867 & 80 & 200 & $\alpha^{\ddagger}$
\end{tabular}

* HCP: $a=5.028 \mathrm{~A}, c \cong 6.433 \mathrm{~A}$.

+ BCT: $a=5.200 \mathrm{~A}, c \cong 6.410 \mathrm{~A}$.

\pm FCC: $a=3.545 \mathrm{~A}$

Lines 3, 8, and 13 correspond to strong reflections of the $\gamma$ - $\mathrm{Co}_{2} \mathrm{Ta}$ compound. Except for the absence of the reflection represented by line 3 in Table 5, alloy $A_{14} B_{14}$ had a similar diffraction pattern.

The effect of increasing the $\mathrm{Ta}$ concentration on the formation of various phases and the intensity of their diffraction lines is summarized in Table 6 . In addition to the formation of new phases, the intensity of the lines of the $\beta$ phase decreased. The intensity of the diffraction lines of the $\sigma$, $\alpha-\mathrm{Co}_{3} \mathrm{Ta}$, and $\gamma-\mathrm{Co}_{2} \mathrm{Ta}$ phases increased with Ta concentration.

\section{Discussion}

The effect of adding Ta to the $40 \mathrm{Co}-30$ $\mathrm{Ni}$-30 Cr alloy base may be classified in three categories.
RAISING THE STACKING FAULT ENERGY The intensity of reflections characteristic of the less ductile HCP $\beta$ phase (Table 6) decreased with increasing Ta concentration. In other words, the addition of $\mathrm{Ta}$ decreased the amounts of $\beta$ phase formed in the alloy; this signifies an increase in the SFE of the alloy by addition of Ta. In this respect, Ta may be considered an element that imparts ductility to the alloy by eliminating the embrittling stacking faults and increasing the concentration of the more ductile $\alpha$ phase.

FORMATION OF INTERMETALLIC COMPOUNDS.Detectable amounts of intermetallic compounds were obtained at $\mathrm{Ta}$ concentrations greater than $5 \%$. The first compound to precipitate was identified as $\alpha \cdot \mathrm{Co}_{3} \mathrm{Ta}$, as in-

TABLE 3

X-Ray Diffraction Data Obtained from Alloy $A_{5} B_{5} \quad(5.7 \%$ Ta) With CR-K RAdiation $_{a}$

\begin{tabular}{|c|c|c|c|c|c|}
\hline Line & $2 \theta$ & $d, \mathrm{~A}$ & $I / I o$ & $h k l$ & Phase \\
\hline 1 & 18.915 & 6.9693 & 05 & 001 & $\sigma^{*}$ \\
\hline 2 & 30.470 & 4.3590 & 30 & 100 & $\beta^{\dagger}$ \\
\hline 3 & 37.430 & 3.5700 & 10 & 100 & $\alpha-\mathrm{Co}_{3} \mathrm{Ta}$ \\
\hline 4 & 41.030 & 3.2685 & 80 & 002 & $\beta^{*}$ \\
\hline 5 & 51.400 & 2.6414 & 05 & 110 & $\alpha-\mathrm{Co}_{3} \mathrm{Tat}$ \\
\hline 6 & 54.090 & 2.5192 & 60 & 110 & $\beta^{\dagger}$ \\
\hline 7 & 59.050 & 2.3244 & 05 & 210 & $\sigma^{*}$ \\
\hline 8 & 61.270 & 2.2485 & 05 & 202 & $\sigma^{*}$ \\
\hline 9 & 63.520 & 2.1762 & 10 & 200 & $\beta$ t \\
\hline 10 & 67.710 & 2.0561 & 100 & 111 & $\alpha^{\S}$ \\
\hline $1 \mathrm{I}$ & 73.640 & 1.9153 & 10 & 103 & $\beta^{\dagger}$ \\
\hline 12 & 79.520 & 1.7910 & 80 & 200 & $\alpha^{\S}$ \\
\hline
\end{tabular}

- BCT: $a=5.200 \mathrm{~A}, \mathrm{c}=6.410 \mathrm{~A}$.

† HCP: $a=5.028 \mathrm{~A}, c=6.439 \mathrm{~A}$.

† Simple cubic: $a=3.647 \mathrm{~A}$.

\$ FCC: $a=3.545 \mathrm{~A}$. 
TABLE 4

X-Ray Diffraction Data Obtained from Alloy $A_{8} B_{8} \quad(10.7 \%$ Ta) With Cr-K Radiation $_{a}$

\begin{tabular}{cccccc}
\hline Line & $2 \theta$ & $d, \mathrm{~A}$ & $I / I_{0}$ & $h k l$ & Phase \\
\hline 1 & 18.79 & 7.0207 & 20 & 001 & $\sigma^{*}$ \\
2 & 30.18 & 4.3999 & 30 & 100 & $\beta^{\dagger}$ \\
3 & 37.86 & 3.5309 & 30 & 100 & $\alpha$ - $\mathrm{Co}_{3} \mathrm{Ta} \ddagger$ \\
4 & 41.02 & 3.2693 & 80 & 002 & $\beta^{\dagger}$ \\
5 & 51.46 & 2.6385 & 05 & 110 & $\alpha$ - $\mathrm{Co}_{3} \mathrm{Ta} \neq$ \\
6 & 56.10 & 2.5141 & 60 & 110 & $\beta^{\dagger}$ \\
7 & 61.01 & 2.2566 & 10 & 210 & $\sigma^{*}$ \\
8 & 62.34 & 2.2131 & 05 & 202 & $\sigma^{*}$ \\
9 & 63.34 & 2.1817 & 10 & 200 & $\beta^{\dagger}$ \\
10 & 67.85 & 2.0524 & 100 & 111 & $\alpha^{\S}$ \\
11 & 73.95 & 1.9044 & 20 & 103 & $\beta^{\dagger}$ \\
12 & 79.75 & 1.7867 & 80 & 200 & $\alpha^{\S}$ \\
\hline
\end{tabular}

- BCT: $a=5.200 \mathrm{~A}, c=6.410 \mathrm{~A}$.

† HCP: $a=5.028$ A, $c=6.433$ A.

$\ddagger$ SC: $a=3.647 \mathrm{~A}$.

$\$ \mathrm{FCC}: a=3.545 \mathrm{~A}$

dicated in Table 3. This compound is known ${ }^{10,11}$ to precipitate coherent with the matrix phase $\alpha$. The coherency of the precipitate should be credited for the high strength and ductility of the alloys presented in part II of this study. 5

The intensity of the reflections characteristic of $\alpha$ - $\mathrm{Co}_{3} \mathrm{Ta}$ (Table 6) increased with Ta concentration; this indicates an increase in the amounts of the precipitate.
In addition to $\alpha-\mathrm{Co}_{3} \mathrm{Ta}$, the incoherent intermetallic compound $\gamma \cdot \mathrm{Co}_{2} \mathrm{Ta}$ was detected in alloys that contained more than $15 \%$ Ta. The precipitation of $\gamma-\mathrm{Co}_{2} \mathrm{Ta}$ may be due to the transformation of the precipitate from the coherent to the incoherent condition. This transformation relieves the system of coherency strains and hence lowers its energy. Naturally, the reduction in the energy of the system can be achieved by

TABLE 5

X-Ray Diffraction Data Obtained from Alloy $A_{15} B_{15}(16.8 \%$ Ta) WITH CR-K $a$ RAdiation

\begin{tabular}{|c|c|c|c|c|c|}
\hline Line & $2 \theta$ & $d, \mathrm{~A}$ & $I / I 0$ & $h k l$ & Phase \\
\hline I & 19.04 & 6.9257 & 30 & 001 & $\sigma^{*}$ \\
\hline 2 & 30.31 & 4.3815 & 30 & 100 & $\beta \dagger$ \\
\hline 3 & 33.37 & 3.9896 & 10 & 101 & $\gamma-\mathrm{Co}_{2} \mathrm{Ta}$ \\
\hline 4 & 37.83 & 3.5336 & 30 & 100 & $\alpha-\mathrm{Co}_{3} \mathrm{Ta} \S$ \\
\hline 5 & 41.13 & 3.2609 & 80 & 002 & $\beta^{\dagger}$ \\
\hline 6 & 52.43 & 2.6213 & 15 & 110 & $\alpha \cdot \mathrm{Co}_{3} \mathrm{Ta}$ \\
\hline 7 & 54.23 & 2.5132 & 40 & 110 & $\beta^{\dagger}$ \\
\hline 8 & 57.89 & 2.3668 & 20 & 110 & $\gamma-\mathrm{Co}_{2} \mathrm{Ta} \ddagger$ \\
\hline 9 & 59.45 & 2.3102 & 20 & 210 & $\sigma^{*}$ \\
\hline 10 & 62.28 & 2.2150 & 10 & 202 & $\sigma^{*}$ \\
\hline 11 & 63.60 & 2.1737 & 10 & 200 & $\beta t$ \\
\hline 12 & 67.31 & 2.0669 & 100 & 111 & $\alpha^{\#}$ \\
\hline 13 & 70.84 & 1.9764 & 20 & 202 & $\gamma \cdot \mathrm{Co}_{2} \mathrm{Ta} \neq$ \\
\hline 14 & 73.27 & 1.9198 & 10 & 103 & $\beta \dagger$ \\
\hline 15 & 78.21 & 1.8160 & 10 & 200 & $\alpha-\mathrm{Co}_{33} \mathrm{Ta}$ \\
\hline 16 & 79.39 & 1.7936 & 80 & 200 & $\alpha^{\#}$ \\
\hline
\end{tabular}

* BCT: $a=5.200 \mathrm{~A}, c=6.410 \mathrm{~A}$

† HCP: $a=5.028 \mathrm{~A}, c=6.433 \mathrm{~A}$.

+ HCP: $a=4.7000 \mathrm{~A}, c=15.42 \mathrm{~A}$

S SC: $a=3.647 \mathrm{~A}$

\# FCC: $a=3.545$ A. 
TABLE 6

Summary of Diffragtion Data Obtained with Gr-K $a$ Radiation

\begin{tabular}{|c|c|c|c|c|c|c|c|}
\hline \multirow[b]{2}{*}{ Line } & \multicolumn{5}{|c|}{ Intensity at Given Ta Concentration } & \multirow[b]{2}{*}{$h k l$} & \multirow[b]{2}{*}{ Phase } \\
\hline & $\begin{array}{c}0 \% \\
A_{1} B_{1}\end{array}$ & $\begin{array}{l}5.7 \% \\
A_{5} B_{5}\end{array}$ & $\begin{array}{c}10.7 \% \\
A_{8} B_{8}\end{array}$ & $\begin{array}{l}15.2 \% \\
A_{14} B_{14}\end{array}$ & $\begin{array}{l}16.7 \% \\
A_{15} B_{15}\end{array}$ & & \\
\hline 1 & 0 & 10 & 20 & 25 & 30 & 001 & $\sigma$ \\
\hline 2 & 50 & 30 & 30 & 30 & 30 & 100 & $\beta$ \\
\hline 3 & . . & . . & $\ldots$ & $\ldots$ & 10 & 101 & $\gamma-\mathrm{Co}_{2} \mathrm{Ta}$ \\
\hline 4 & $\ldots$ & 10 & 30 & 30 & 30 & 100 & $\alpha-\mathrm{Co}_{3} \mathrm{Ta}$ \\
\hline 5 & 90 & 90 & 70 & 70 & 70 & 002 & $\beta$ \\
\hline 6 & $\ldots$ & 05 & 05 & 15 & 15 & 110 & $\alpha \cdot \mathrm{Co}_{3} \mathrm{Ta}$ \\
\hline 7 & 60 & 60 & 60 & 40 & 40 & 110 & $\beta$ \\
\hline 8 & $\ldots$ & $\ldots$ & $\ldots$ & 10 & 20 & 110 & $\gamma-\mathrm{Co}_{2} \mathrm{Ta}$ \\
\hline 9 & 05 & 05 & 10 & 10 & 20 & 210 & $\sigma$ \\
\hline 10 & 05 & $\cdots$ & 05 & 05 & 10 & 202 & $\sigma$ \\
\hline 11 & 20 & 10 & 10 & 10 & 10 & 200 & $\beta$ \\
\hline 12 & 100 & 100 & 100 & 100 & 100 & 111 & $\alpha$ \\
\hline 13 & $\cdots$ & $\cdots$ & $\cdots$ & 10 & 20 & 202 & $\gamma \mathrm{Co}_{2} \mathrm{Ta}$ \\
\hline 14 & 20 & 10 & 20 & 10 & 10 & 103 & $\beta$ \\
\hline 15 & $\cdots$ & . . & $\cdots$ & 10 & 10 & 200 & $\alpha-\mathrm{Co}_{3} \mathrm{Ta}$ \\
\hline 16 & 80 & 80 & 80 & 80 & 80 & 200 & $\alpha$ \\
\hline
\end{tabular}

transformation from coherent $\mathrm{Co}_{3} \mathrm{Ta}$ to incoherent $\mathrm{Co}_{3} \mathrm{Ta}$; however, there is another reason for the transformation from $\mathrm{Co}_{3} \mathrm{Ta}$ to $\mathrm{Co}_{2} \mathrm{Ta}$.

Precipitation is defined as the formation of a new phase as a result of supersaturation produced by a change in temperature. In other words, precipitation reduces the concentration of solute atoms in the matrix. At Ta concentrations less than $15.2 \%\left(A_{14} B_{14}\right)$, precipitation of $\alpha-\mathrm{Co}_{3} \mathrm{Ta}$ took place. This compound contains 25 atomic\% $\%$ a. At $\mathrm{Ta}$ concentrations greater than $15.2 \%$, the precipitation of a compound that has 25 atomic $\% \mathrm{Ta}$ will result in a matrix that is still oversaturated in Ta. To eliminate such oversaturation, a compound that eliminates more $\mathrm{Ta}$ than $\mathrm{Co}_{3} \mathrm{Ta}$ is necessary. The precipitation of $\mathrm{CO}_{2} \mathrm{Ta}$ (33.3 atomic\% $\%$ Ta) seems to be the mechanism through which oversaturation is avoided.

INCREASING THE CONCENTRATIONS OF THE $\sigma$ PHASE.-The effect of increasing Ta concentration on the intensity of reflections characteristic of $\sigma$ phase (Table 6) indicates that the amounts of $\sigma$ formed in the alloy increase significantly only when $\mathrm{Ta}$ concentration constitutes more than $10 \%$ of the alloy. This indicates that the critical average electron hole number $\left(\bar{N}_{v}\right)$ of the alloy system is exceeded at that concentration of Ta. This reasoning also was supported by the metallographic examination evidence in part III of this study. ${ }^{2}$

\section{Conclusions}

The experimental evidence in this article suggests the following conclusions: The addition of $\mathrm{Ta}$ to the $\mathrm{Co}-\mathrm{Ni}-\mathrm{Cr}$ system restricts the field of the HCP phase and hence contributes to increasing the ductility of the alloy. Tantalum reacts with Co to form the intermetallic compound $\alpha-\mathrm{Co}_{3} \mathrm{Ta}$, which is the major strengthener in the alloys in this study. Excessive use of $\mathrm{Ta}$ contributes to the formation of harmful phases such as $\gamma-\mathrm{Co}_{2} \mathrm{Ta}$ (Laves's compound) and the $\sigma$ phase.

\section{References}

1. Mohammed, H., and Ascar, K.: A New Dental Superalloy System: I. Theory and Alloy Design, $J$ Dent Res 52: 136-144, 1973.

2. Mohammed, H.; Asgar, K., and Bigelow, W.G.: A New Dental Superalloy System: III. Microstructure and Phase Transformation, $J$ Dent Res 52: 151-156, 1973.

3. AsGar, K.: The Relationship Between the Physical Properties and Microstructure of Chromium-Cobalt Base Alloy Used in Dentistry, thesis, University of Michigan, Ann Arbor, Mich, 1959.

4. Johnson, R.S., JR.: Determination of a Partial Room-Temperature Ternary Constitution Diagram in the As Cast Cr-Co-Ni Sys- 
tem Utilizing a Factorial Experimental Design, thesis, University of Michigan, Ann Arbor, Mich, 1970.

5. Mohammed, H., and Asgar, K.: A New Dental Superalloy System: II. Mechanical Properties, J Dent Res 52: 145-150, 1973.

6. AZARofF, L.V., and Buerger, M.L.: The Powder Method in X-Ray Crystallography, New York: McGraw-Hill, 1958, 342 p.

7. Cullity, B.D.: Elements of X-Ray Diffraction, Reading, Mass.: Addison-Wesley, 1967. $515 \mathrm{p}$.

8. Elsea, A.R.; Westermann, A.B.; and ManNING, G.K.: The Cobalt Chromium Binary System Trans AIME 180: 579, 1949.
9. Manly, W.D., and Beck, P.A.: Survey of the Chromium-Cobalt-Nickel Phase Diagram at $1200 \mathrm{C}$, National Advisory Committee for Aeronautics (TN-2602), February 1592.

10. Drapier, J.M.; Bouwer, J.L.; and CoutsourADIs, D.: Refractory Metals and Intermetallic Precipitates in Cobalt-Chromium Alloys Cobalt 27:59, June 1965.

11. Korchynsky, M., and Fountain, R.W.: Precipitation Phenomena in Cobalt-Tantalum Alloys, Trans AIME 215: 1033, 1959.

12. DRAGSDORF, R.D., and Forgeng, W.D.: Intermetallic Phases in the Cobalt-Tantalum System, Acta Crystallogr 15: 531, 1962. 